\title{
Emotions, Behavior, and the Mediating Role of Climate
}

\author{
Taghrid S. Suifan ${ }^{1}$ \\ ${ }^{1}$ School of Business, The University of Jordan, Amman, Jordan \\ Correspondence: Taghrid S. Suifan, School of Business, The University of Jordan, Amman, Jordan. Tel: 962-6535- \\ 5000. E-mail: t.suifan@ju.edu.jo \\ Received: October 5, 2018 \\ doi: $10.5539 /$ mas.v12n12p145 \\ Accepted: October 16, $2018 \quad$ Online Published: November 19, 2018 \\ URL: https://doi.org/10.5539/mas.v12n12p145
}

\begin{abstract}
This study examined the impact of emotional intelligence on organizational citizenship behavior with organizational climate as the mediator, in the context of Jordanian pharmaceutical companies. The study addresses the gap in the research that examines the mediating effect organizational climate has on organizational citizenship behavior and emotional intelligence. Quantifiable data were collected using a survey questionnaire, and statistical analyses were performed, including correlation and regression analysis. This study indicates that organizational climate is of great importance in Jordanian pharmaceutical companies because it tended to promote efficiency and effectiveness among employees. Organizational climate mediates the relationship between emotional intelligence and organizational citizenship behavior; if emotionally intelligent employees are provided with a positive organizational climate, only then can they contribute positively towards organizational citizenship behavior. The study is helpful in understanding how organizational citizenship behavior has become a factor underlying job satisfaction. Therefore, Jordanian pharmaceutical companies should focus on developing a culture in which employees can achieve goals and feel satisfied.
\end{abstract}

Keywords: emotional intelligence, Jordan, organizational climate, organizational citizenship behavior, pharmaceutical companies

\section{Introduction}

\subsection{Background}

Emotions are unavoidable in an organizational context: individuals feel happiness and pride regarding their achievements or hopelessness regarding their failures (Khalili, 2017). In the workplace, these emotions may affect organizational behavior (Koning \& Kleef, 2015). Research suggests than an employee displays more positive behavior when an ethical work climate is present than when it is lacking (Lau, Tong, Lien, Hsu, \& Chong, 2017). Asgarian, Aghajani, and Alavi (2017) define emotional intelligence (EI) as a factor that allows employees to understand and evaluate their emotions more accurately. EI is defined as the ability to monitor one's emotions and the emotions of others, discriminating among them to extract information to guide actions (Salovey \& Mayer, 1990). Organ (1988) defines organizational citizenship behavior (OCB) as discretionary behavior that is recognized by a reward system and promotes the effective functioning of the organization (p. 331). The demand for OCB has significantly increased due to a rise in global competitiveness and the need for continuous innovation (Tinti, Venelli-Costa, Vieira, \& Cappellozza, 2017). Organizational climate (OC) allows for a more positive employee perception, which increases employee performance and knowledge management (Naldoken \& Tengilimoglu, 2017).

Although there is little research on OC mediating OCB and EI's relationship, this study hopes to reveal the levels of EI that will explain an employee's level of OCB as long as the organizational climate (OC) is positive and nurturing of the EI and OCB relationship.

Currently, there is a lack of empirical research that highlights the relationship between EI and OCB mediated by OC (Anvari, Barzaki, Amiri, Irum, \& Shapourabadi, 2017; Arda, Delen, Tatoglu, \& Zaim, 2017). Current research discusses and analyzes EI, OCB, and OC on the following sub-dimensions. First, self-awareness, self-management, social awareness, and emotional regulation are examined to determine EI (Libbrecht, Lievens, \& Schollaert, 2010; Wong \& Law, 2002). Second, human relations, internal processes, open systems, and rational goals are studied to measure OC (Patterson et al., 2005). Finally, job satisfaction, employee loyalty, and organizational commitment are examined as OCB dimensions (Lee \& Allen, 2002). The current study is significant as it deepens the 
understanding of the role EI plays in the effect of OC on OCB, specifically in pharmaceutical companies in Jordan. As there is little to no literature assessing OCB, EI, or OC in Jordanian pharmaceutical companies, this study aims to asses them specifically in this sector. This is important because Jordan has the most advanced and widely used healthcare system in the MENA region.

Alfonso, Zenasni, Hodzic, and Ripoll (2016) concluded that workers with high levels of EI strengthen the workplace environment, eventually leading to trust. According to Abraham (2004), this trust enhances cooperation and teamwork, which stimulates others to act similarly, strengthens their beliefs and commitment, and leads to improved OCB. Recently, OCB has been identified as employee behavior that provides organizations with a better chance of success and higher effectiveness (Anvari et al., 2017). In other words, it is the behavior that is the outcome of the OC. OC is the importance of and the behavioral outcome of the perception of organizations in terms of practice, policy, procedures, routine, and rewards (Bowen \& Ostroff, 2004). This is later referred to as the good intentions of an organization's members and their level of loyalty to the organization (Gul, 2008).

\subsection{Research Problem}

Much of the existing research does not cover the impact of EI on OCB mediated by OC; rather, it explores the outcome of job satisfaction on OCB. In other words, current research simply discusses a general perception about EI and its effects on a certain sector (Biswas \& Mazumder, 2017; Lewis, Eccles, Mackay, \& Robinson, 2017).

The following studies have investigated specific techniques used to increase service levels and therefore have relevant findings for pharmaceutical company behavior (Rafiei, 2017). Taherinejad, Ahmadi, Amani, and Khoshouei (2017) examine EI's impact on OCB and reveal its importance as a means of enhancing performance and lowering absenteeism. Parke and Seo (2017) explain that managers recognize certain expressions' positive functions, such as smiling at customers, that increase customer satisfaction; thus, EI requires interpersonal relationships and empathy to be more effective (Waruwu, 2015). This suggests that EI has an impact on OC. Additionally, Taherinejad et al. (2017) suggest that a workforce with a poor sense of loyalty, obligation, and commitment is incompatible with organizational goals.

A gap exists in the literature that examines the impact of EI on OCB: the meditating role of OC in Jordanian pharmaceutical companies. Further research must be conducted so that companies have a better understanding in advance of how OCB develops in employees (Arda et al., 2017).

\subsection{Research Objectives}

Primary objective:

1. Examine EI's impact on OCB and OC's mediating role on pharmaceutical companies in Jordan.

Secondary objectives:

1. To examine the impact of EI on OCB and OC's meditating role.

2. To determine the relationship between EI and OCB.

3. To determine the relationship between EI and OC.

4. To examine OC's mediating effect on OCB.

5. To provide pharmaceutical company managers with a deeper understanding of employee behavior and its impact on their organizations.

\subsection{Research Significance}

The expanding pharmaceutical industry in Jordan has become more professional and organized in recent years with detailed laws and regulations governing the private sector (Daher \& Alabbadi, 2017). The factors chosen for this study-EI, OCB, and OC - are mostly associated with service sectors that reflect their importance for the organizational level (Taherinejad et al., 2017).

Healthcare in Jordan is known for its high quality and standards; the majority $(62 \%)$ of health expenditures are financed through public funding and only $34.5 \%$ is financed by the private sector (Daher \& Alabbadi, 2017). The study also found that Jordanian pharmaceutical companies, which are private, are subject to strict laws and regulations. Thus, this study is significant because it could provide such companies with a better understanding of employee behaviors. This knowledge will, in turn, empower pharmaceutical companies in Jordan to improve their OC with the ultimate goal of enhancing OCB. 


\section{Literature Review}

\subsection{EI and $O C B$}

Understanding and regulating one's emotions improves organizational behavior (Khalili, 2016); therefore, it is important for both employees and managers to be able to regulate their emotions to socially influence others (Van Kleef, Van Doorn, Heerdink, \& Koning, 2011). Employees with high EI can regulate their own and others' emotions better. EI and OCB lead to better relationships with colleagues by creating a positive work environment (Alfonso et al., 2016).

EI, according to Wong and Law (2002), can be separated into four components: self-awareness, self-management, social awareness, and emotional regulation. Self-awareness is the ability to understand and express emotions naturally (Carvalho, Guerrero, Chambel, \& González-Rico, 2016). Self-management is the generation of emotions, as well as understanding how moods impact thinking and relate feelings to thoughts (Omoregbee, Morrison, \& Morrison, 2016). Interpersonal skills build the foundation for EI, and it is essential for organizations to ensure that their managers possess these skills in order to enhance empathy toward their subordinates. In turn, employees feel safe and productive, which contributes to organizational success (Shafiq \& Rana, 2016). Consistent with this finding, Alfonso et al. (2016) concluded that EI creates a positive working environment. Finally, the regulation of emotions implies remaining open to emotions and integrating them with cognitive emotional thinking to make more effective decisions (Carvalho et al., 2016). Focusing on employee job satisfaction is critical, as it will lead to generating the seriousness and motivation necessary for carrying out goals and tasks (Waruwu, 2015). Employees with emotional attachments to colleagues, when contemplating quitting, will stay with the organization to seek personal fulfillment and because they feel that staying is essential (Shafiq \& Rana, 2016). Social awareness is the ability to understand the emotions of others and provide feedback to the appropriate emotion (Omoregbee et al., 2016); this ability is vital in ensuring employee satisfaction and OCB.

According to Lee and Allen (2002), OCB can be broken down into three main areas: job satisfaction, organizational commitment, and employee loyalty. Particularly when employees lack a sense of obligation, research has linked low job satisfaction with lower attention to employee needs from superiors, resulting in high absenteeism (Waruwu, 2015). Organizational commitment has many counterparts, some involving the affirmative feelings of belongingness and attachment to the organization's affairs (Shafiq \& Rana, 2016). Loyalty requires a number of positive circumstances in addition to providing employees with high salaries and benefits (Klopotan, Buntak, \& Drožđek, 2016).

Shafiq and Rana (2016) suggest that employees' organizational commitment and job satisfaction in relation to the interpersonal skills needed for EI may play a significant role in an organization's functional improvement. Committed, loyal employees are always compatible with organizational goals and values that extend beyond responsibilities stated in the job description (Taherinejad et al., 2017). Organizational commitment describes the obligation to remain in the organization, providing the degree of commitment employees feel towards the organization when they consider penalties of quitting (Shafiq \& Rana, 2016). Employee loyalty is one of the most essential positive interpersonal relationships that a manager in a company can achieve (Klopotan et al., 2016). Organizational commitment positively correlates with the interpersonal skills required for EI (Shafiq \& Rana, 2016).

\subsection{EI and $O C$}

Although important in developing an effective organizational climate, EI has been perceived differently by various scholars (Kauts \& Chechi, 2014). Awwad and Ali (2012) cite the positive relationship between EI and OC and determined managers' EI is key to improving OC for employees because it creates an atmosphere that encourages employees to give their best. Parke and Seo (2017) found that scholars conceptualize organizational climate in terms of goals and values and understand employees' perception of goal importance based on how they regulate their emotions. For example, employee enthusiasm pays off in the form of improved business performance when developed from EI (Awwad \& Ali, 2012).

Some have considered EI to be a consequence of the provided environment while others regard it as a learning ability and the result of self-concept (Kauts \& Chechi, 2014). Emotionally intelligent leadership is often crucial in creating a working climate that encourages employees to give their best, which in turn pays off in improved business performance (Awwad \& Ali, 2012). A positive OC allows employees to perform behaviors that align with the organization's objectives (Parke \& Seo, 2017). Some researchers also believe that EI is the result of experience (Kauts \& Chechi, 2014). In addition, EI influences organizational effectiveness in areas such as employee recruitment and retention, talent development, teamwork, and employee commitment (Kauts \& Chechi, 2014). In summary, EI exerts a strong, positive influence on OC, which is necessary for enabling systematic problem-solving 
and can aid in organizational decision-making (Awwad \& Ali, 2012).

Conversely, OC includes the following important factors: human relations, internal processes, open systems, and rational goals (Patterson et al., 2005). Human relations refer to relationships among organizations' employees (Ali, $\mathrm{Li}, \& \mathrm{Wei}, 2017)$. Internal process refers to an approach represented by formalization and tradition, where the organization's internal focus and control lies in using resources efficiently (Patterson et al., 2005). Open systems are the organization's interactions and adaptations in its environment, with managers seeking resources and innovating in response to environmental demands (Bernstrøm, Lone, Bjørkli, Ulleberg, \& Hoff, 2013). Having rational goals is represented by the clarity of organizational goals, efficiency, effort, performance feedback, pressure to produce, and quality (Patterson et al., 2005).

EI's strong influence on OC is linked to how organizations promote emotions (Awwad \& Ali, 2012). According to Grandey and Gabriel (2015) and Kegan, Lahey, Fleming, and Miller (2014), organizations intentionally and unintentionally promote their desired emotions among employees through regulation of emotions and climate perceptions, which can be deliberate and formal or unintentional and informal (Parke \& Seo, 2017). Morale and health, innovation, productivity, efficiency, sales, revenues, service quality, and customer loyalty, among other factors, are influenced by EI (Kauts \& Chechi, 2014).

\section{$2.3 O C$ and $O C B$}

According to Organ (1988), OCB is an unrestricted behavior from a person that is not related to any official reward mechanism nor helps a company operate efficiently. The relationship between OCB and OC is mediated by transformational leadership (Kao, 2017). Podsakoff, Whiting, Podsakoff, and Blume (2009) reveal an inverse relationship between OCB and one's intention to leave the company. Some studies also reveal that OC and organizational commitment act as predictors of OCB (Ahmadizadeh, Heydarinejad, Farzam, \& Boshehri, 2012). OC's positive effect on employees ultimately leads to the achievement of organizational objectives (Randhawa \& Kaur, 2015). Thus, OCB is largely dependent upon and influenced by management's attitude and willingness to create such a climate (Kao, 2017). Happy employees are more cooperative, have more respect towards others, and are more inclined to demonstrate OCB (Avey, Wemsing, \& Luthans, 2008; Whitman, Van Rooy, \& Viswesvaran, 2010).

A positive OC in particular can be a predictor for OCB by motivating employees to perform their tasks (Ahmadizadeh et al., 2012; Maamari \& Messarra, 2012). According to Ahmadizadeh et al. (2012), OCB cannot be motivated by awards or formal motivations. Managers can, however, motivate employees by actively establishing suitable contexts and conditions in the organization (Kao, 2017). Furthermore, job satisfaction and organizational commitment have positive effects on OCB and OC; however, how a person acts in an organization depends on personality type, organizational role, and organizational position and situation (Ahmadizadeh et al., 2012).

A more thorough understanding of the benefits of a positive OC and how it affects OCB increases a company's chances of success, as exhibiting empathy and compassion towards employees are important ways to maintain happiness and productivity (Anvari et al., 2017). The OC may inspire and encourage employees to perform beyond their specified job roles (Randhawa \& Kaur, 2015). Therefore, OCB is influenced by OC (Ahmadizadeh et al., 2012).

Employees may potentially be motivated by their leaders to create a positive OC, which provides a satisfactory climate for OCB (Kao, 2017). Further, OC factors, such as communication, rewards, decision-making, and supervisory support, have been found to greatly influence employees' citizenship behavior (Randhawa \& Kaur, 2015). OC, as a set of mental situations that strongly affect organizational circumstances, is a critical, basic element in determining organizational efficiency (Ahmadizadeh et al., 2012). Moreover, an organization's success can be influenced by the growing understanding of OC and the behavioral outcome (Anvari et al., 2017). Nevertheless, it is difficult to provide the highly effective OC required for employees to contribute beyond their assigned tasks (Tsai \& Wu, 2010).

OC influences individual behavior as people strive to be consistent with the environment to achieve balance and self-resistance (Ahmadizadeh et al., 2012). An organization's success mainly depends on managers' skills in providing a more positive, suitable OC (Kao, 2017).

\subsection{Mediating Effect of OC on EI and OCB}

$\mathrm{OC}$ is the environment that reveals organizational members' good intentions and level of organization loyalty (Gul, 2008). An employee's commitment is representative of his/her pride and connection with the organization, which ultimately increases OCB (Indarti, Solimun, \& Hakim, 2017). OC is a strong belief in and the acceptance of organizational goals and values (Adeoye \& Torubelli, 2011). Emotional intelligence was found to be positively 
correlated with well-being, coping with problems, and perceived competence whereas negatively related to perceived stress (Barriball, Fitzpatrick, \& Roberts, 2011). Employees with high EI are skillful at identifying, interpreting, and responding to emotions (Turnipseed \& Vandewaa, 2012), and EI is one of the indicators that leads to improved employee performance (Tofighi, Tirgari, Fooladvandi, Rasouli, \& Jalali, 2015). OCB, in turn, is rooted in employee satisfaction; when employees are dissatisfied with their job, they tend to behave negatively (Hakim \& Fernandes, 2017).

EI and OCB are known to elevate organizational social credibility (Taherinejad et al., 2017). Employees with high EI may perceive and interpret organizational stimuli differently and engage in a different pattern of behavior, including citizenship; therefore, employees high in EI can be expected to have a greater propensity to help peers (Turnipseed \& Vandewaa, 2012). Professional manner, EI, and mental health may also lead employees to good OCB (Tofighi et al., 2015).

The level of an employee's psychological attachment to the organization (organizational commitment) can help predict whether an emotionally intelligent worker is committed to organizational goals (Adeoye \& Torubelli, 2011). Emotionally intelligent managers develop a positive organizational climate to produce OCB (Parke \& Seo, 2017). The ability to understand emotions and to reason with others is a requisite to EI (Turnipseed \& Vandewaa, 2012).

Organizations need committed workers in order to handle worldwide economic competition. Organizational commitment is a willingness to exert considerable effort on behalf of the firm and a strong desire to remain in the organization (Adeoye \& Torubelli, 2011). Commitment and OCB are interrelated with the employers' effective use of EI and how they regulate OC (Indarti et al., 2017). Organizational commitment is a function of several variables such as job satisfaction, motivation, decision making, and organizational support (Adeoye \& Torubelli, 2011). Loyalty, which constitutes an effective response to and identification with an organization based on a sense of duty and responsibility, is often the result of organizational commitment (Adeoye \& Torubelli, 2011). Through loyalty, the employee is regarded as an organizational citizen and encouraged to transcend official duties (Rafiei, 2017). Organizational commitment is an attachment to the organization leading to particular job-related behaviors (Adeoye \& Torubelli, 2011).

An individual with the ability to understand emotion may be likely to engage in discretionary OCB (Turnipseed \& Vandewaa, 2012). Employees who are dissatisfied with their job tend to underperform and rarely put forth extra effort (Hakim \& Fernandes, 2017). The process to develop commitment may involve self-reinforcing cycles of attitudes and behaviors that evolve on the job and eventually strengthen employee commitment to the organization (Adeoye \& Torubelli, 2011). The extra role played by individuals in the form of employee commitment is crucial for organization effectiveness and performance improvement (Indarti et al., 2017).

EI plays a vital role in organizational effectiveness (Adeoye \& Torubelli, 2011). Waruwu (2015) addressed perceptions of EI and OC and assumed that relationships and personal treatment between subordinates and superiors is affected by EI. In general, companies whose members lack loyalty experience an undermined spirit of cooperation and create a culture of indifference toward organizational problems; ultimately, organizational success is delayed (Taherinejad et al., 2017). Emotionally intelligent people display cooperation, commitment, and creativity, which are important for organizational effectiveness (Adeoye \& Torubelli, 2011). Further, Kao (2017) suggests that with a positive OC, employee OCB increases.

EI differs from other intelligence as it deals with the management of emotions and the complex process linking emotion and cognition (Adeoye \& Torubelli, 2011). Job satisfaction is influenced by OC and superiors' interpersonal skills of EI, which can develop factors leading to OCB (Waruwu, 2015). Individuals with high EI are less likely to lose control of their emotions (Turnipseed \& Vandewaa, 2012). Understanding and regulating one's emotions, as well as understanding other's emotions, are factors that affect intrapersonal well-being and interpersonal relations, which, in turn, affects workers' attitudes towards their colleagues, bosses, jobs, and the organization as a whole (Adeoye \& Torubelli, 2011). The tendency to internalize and identify with the organization's goals, norms, and values is associated with OCB (Minibas-Poussard, Le Roy, \& Erkmen, 2017). In summary, proper personal treatment and empathy shown from superiors to subordinates is related to $\mathrm{OCB}$, and in turn, creates a positive OC (Waruwu, 2015).

Clark and Polesello (2017) explain that EI is a means of producing the skills and resulting behaviors needed to create inclusive organizational environments. When employees become indifferent to rewards and reinforcements, they tend to attribute it to external factors, such as employer EI and OC (Minibas-Poussard et al., 2017). Clark and Polesello (2017) propose that the ability to recognize other's and one's own emotions, adapt to moods, and use emotions to solve problems are associated with a positive effect on performance, which establishes satisfaction and allows the employee to manufacture OCB. Zhang and Shi (2017) also mention that positive OCB focuses on 
employee well-being in the workplace; the more emotionally intelligent employees are, the more they can regulate their emotions and moods to properly relate it to positive OC.

In particular, past studies revealed that EI influences organizational leaders and managers such that it leads to the development of positive relationships with not only colleagues but also employees at different levels of the organization (Mittal \& Sindhu, 2012). For instance, self-management, as a factor of EI, encourages leaders as well as employees to develop an understanding of how mood influences thinking (Boyatzis, Goleman, \& Rhee, 2000). The organization can then offer leaders and managers an opportunity to develop and enhance empathy within the organization, ultimately leading to the employee motivation; since they feel safe and secure, productivity and organizational success increase (Wolff et al., 2002).

\section{Methodology and Materials}

\subsection{Research Model}

The research model presented in Figure 1 is based on conclusions drawn from the literature discussing the impact of EI on OCB with the mediating role of OC.

Independent Variable

Independent Variable

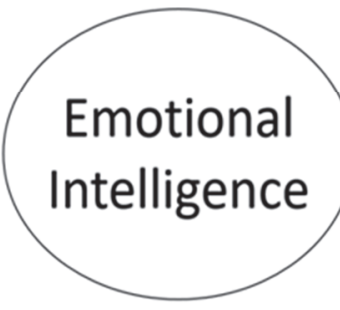

Mediating Variable

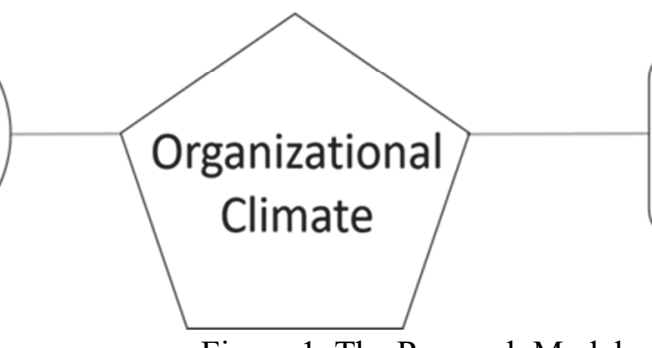

Dependent Variables

Figure 1. The Research Model.

\subsection{Research Hypotheses}

H0.1: There is no significant relationship between EI and OCB.

H0.2: There is no significant relationship between EI and OCB, mediated by OC.

H0.3: There is no significant relationship between EI and OC.

H0.4: There is no significant mediating effect of OC on OCB.

\subsection{Operational Definitions}

To clarify the research model's independent, mediating, and dependent variables, necessary definitions are provided in this section, as well as the measurement instruments used.

\subsubsection{Emotional Intelligence}

To measure EI, the scale adopted from Wong and Law's (2002) WLEIS was used. In total, 16 items were measured using a 5-point rating scale ranging from "1 (strongly disagree)" to "5 (strongly agree)."

- $\quad$ Self-awareness (4 items)

- The ability to understand and naturally express deep emotions (Carvalho et al., 2016). This also means accurately identifying the causes of emotions and being able to predict how emotions change and blend (Omoregbee et al., 2016).

- Self-management (4 items)

- The generation of emotions and understanding of how moods impact thinking, how feelings relate to thoughts, and how to use problem-solving skills and communication to facilitate one's own emotions (Omoregbee et al., 2016). Self-management is the ability to utilize emotions by directing them towards constructive activities and personal performance (Carvalho et al., 2016).

- Social awareness (4 items) 
- The ability to use faces, landscapes, and designs to read people's emotions and provide feedback (Omoregbee et al., 2016).

- Regulation of emotions (4 items)

- The ability to self-regulate emotions, stay open to emotions, and integrate emotions with thinking to make more effective decisions (Carvalho et al., 2016; Omoregbee et al., 2016).

\subsubsection{Organizational Climate}

$\mathrm{OC}$ refers to the environment surrounding employees in an organization and the events that occur in a behaviorally oriented manner (Schneider, 2000). To measure OC, the Organizational Climate Measure (OCM) scale developed by Patterson et al. (2005) was used. In total, 55 items were measured using a 5-point rating scale ranging from "1 (strongly disagree)" to "5 (strongly agree).":

- Human relations (19 items)

- The organization's internal climate that includes relationships among employees and between employees and employers and how these relationships are managed (Ali et al., 2017). The human relations approach is represented by autonomy, integration, involvement, supervisory support, emphasis on training, and employee welfare (Patterson et al., 2005).

- Internal processes (6 items)

- The internal processes approach is represented by formalization and tradition; internal focus and tight control exists within the organization to establish efficient resource use (Patterson et al., 2005).

- Open systems (12 items)

- The open systems approach includes innovation and flexibility, outward focus, and reflexivity; it emphasizes the organization's interactions and adaptations in its environment, with managers seeking resources and innovating in response to environmental demands (Bernstrøm et al., 2013; Patterson et al., 2005).

- Rational goals (18 items)

- The rational goal approach is represented by clarity of organizational goals, efficiency, effort, performance feedback, pressure to produce, and quality, reflecting a rational economic model of organizational functioning in which the emphasis is on productivity and goal achievement (Bernstrøm et al., 2013; Patterson et al., 2005).

\subsubsection{Organizational Citizenship Behavior}

OCB is a concept that bridges an individual's work satisfaction and performance; it is a major topic discussed in recent years due to its importance in organizational survival (Brenner, Lyons, \& Fassinger, 2010). To measure OCB, the scale adopted from Lee and Allen's (2002) "Organizational Citizenship Behavior Individual" was used. In total, 11 items were measured using a 5-point rating scale ranging from 1 (strongly disagree) to 5 (strongly agree).:

- Job satisfaction (3 items)

- Employees' helpful and positive feelings after performing a task (Talachi, Gorji, \& Boerhannoeddin, 2014).

- Organizational commitment (4 items)

- The concept of employees working to maintain the organization's continuity (Indarti et al., 2017).

- Employee loyalty (4 items)

- The level of organization acceptance and internalization rooted in the employee. It entails promoting the organization to outsiders, protecting and defending it against external threats, and remaining committed to it even under adverse conditions (Jauhari \& Singh, 2013; Muldoon, Keough, \& Liguori, 2017).

\subsection{Materials}

Quantitative data were collected using a questionnaire. The questionnaire consisted of three parts, the first being a short covering letter explaining the purpose of the survey and confirming the confidentiality of the responses. The second part collected basic demographic information. The third part was the main questionnaire consisting of 82 
items assessed on a 5-point Likert scale to allow respondents to express how much they agreed or disagreed with each statement.

Heads of department, supervisors, and non-managerial employees in 14 pharmaceutical manufacturing companies in Jordan were selected for this study. A stratified random sample was used based on the number of employees in each company. The total number of employees was 5,484. The size of the sample taken was 361 as recommended by Sekaran and Bougie (2016). A total of 337 questionnaires were retrieved, which composed (93\%) of questionnaires distributed by the researcher.

Of the 337 respondents, $57.6 \%$ were male, whereas $42.4 \%$ were female. Most were 30 to 40 years old ( $86.3 \%)$, held a bachelor's degree (65.6\%), and were employed at a non-managerial level $(93.5 \%)$.

\section{Research Results}

Results were triangulated with available secondary information, which included past studies using a similar method.

A reliability analysis was performed on the data to evaluate the internal consistency of the measurement instrument and to ensure that the results were statistically significant (Bonett \& Wright, 2015). Table 1 displays the case processing summary of this research; all the 350 participant responses were considered to evaluate the consistency of the instrument and variables.

Table 1. Reliability Analysis - Case Summary

\section{Case Processing Summary}

\begin{tabular}{llll}
\hline & & $\mathrm{N}$ & $\%$ \\
\hline Cases & Valid & 350 & 100.0 \\
& Excluded $^{\mathrm{a}}$ & 0 & .0 \\
& Total & 350 & 100.0
\end{tabular}

a. List-wise deletion based on all variables in the procedure.

Table 2 shows the reliability statistics for the set of items/variables. The Cronbach's alpha is not a statistical test but a coefficient of reliability or consistency. The three items in Table 2 represent the independent, dependent, and mediating variables. Generally, anything above 0.70 is considered acceptable in terms of reliability (Nunnally, 1978); the value of 0.836 means the model's internal consistency was highly consistent and that the study's findings are appropriate and accurate.

Table 1. Reliability Analysis - Reliability Statistics

\section{Reliability Statistics}

\begin{tabular}{cc}
\hline $\begin{array}{c}\text { Cronbach's } \\
\text { Alpha }\end{array}$ & N of Items \\
\hline .836 & 3 \\
\hline
\end{tabular}

Correlation was used to evaluate the relationship among independent and dependent variables (Hinton, McMurray, $\&$ Brownlow, 2014). In this correlation analysis, EI was the independent variable, OC the mediating variable, and OCB the dependent variable. The researcher predicted a connection among variables, and the relationship among each variable is presented in Table 3 . The values of the Pearson correlation coefficient and the significance value were also important in the correlation assessment, as the Pearson correlation coefficient shows the strength of interdependence between two variables. Any value less than 0.3 indicates a weak correlation, a value from 0.3 to 0.7 indicates a moderate correlation, and any value above 0.7 indicates a strong interdependence among the variables (Ratner, 2009). In order to determine the statistical significance of the test, the sig value was interpreted; a sig value less than the acceptance value of 0.05 indicates significant correlation results. 
Table 3. Correlation Analysis

\section{Correlations}

\begin{tabular}{ccccc}
\hline & & $\begin{array}{c}\text { Emotional } \\
\text { Intelligence }\end{array}$ & $\begin{array}{c}\text { Organizational } \\
\text { Climate }\end{array}$ & $\begin{array}{c}\text { Organizational } \\
\text { Citizenship } \\
\text { behavior }\end{array}$ \\
\hline Emotional Intelligence & Pearson Correlation & 1 & $.696^{* *}$ & $.552^{* *}$ \\
& Sig. (2-tailed) & & .000 & .000 \\
Organizational Climate & $\mathrm{N}$ & 350 & 350 & 350 \\
& Pearson Correlation & $.696^{* *}$ & 1 & $.734^{* *}$ \\
& Sig. (2-tailed) & .000 & & .000 \\
Organizational & $\mathrm{N}$ & 350 & 350 & 350 \\
Citizenship behavior & Pearson Correlation & $.552^{* *}$ & $.734^{* *}$ & 1 \\
& Sig. (2-tailed) & .000 & .000 & 350 \\
\hline
\end{tabular}

**. Correlation is significant at the 0.01 level (2-tailed).

The results of the analysis are as follows. The independent variable was EI, while the dependent variable of the research was OCB. The Pearson correlation coefficient of 0.552 means that the interdependence of EI and OCB was moderate. The sig value for both values was 0.000 , which was less than the alpha value; hence, it can be said that these results were statistically significant.

The mediating variable was OC, while the dependent variable was OCB. The Pearson correlation coefficient of 0.734 means that the interdependence of OC and OCB was high. The sig value for both values was 0.000 , which was less than the alpha value; hence, it can be said that these results were statistically significant.

Regression analysis was conducted to predict the impact of the independent variable on the dependent (Menard, 2018). Regression analysis was performed using SPSS statistics version 22.0 to determine the impact of EI on OCB in Jordanian pharmaceutical companies, with OC being the mediating variable. To conduct a simple regression test, the mediating variable was also treated as the independent variable; therefore, EI and OC were the independent variables while OCB was the dependent variable. Table 4 presents the model summary of the regression analysis.

Table 4. Regression Analysis - Model Summary

Model Summary

\begin{tabular}{ccccc}
\hline Model & $\mathrm{R}$ & R Square & $\begin{array}{c}\text { Adjusted R } \\
\text { Square }\end{array}$ & $\begin{array}{c}\text { Std. Error of } \\
\text { the Estimate }\end{array}$ \\
\hline 1 & $.835^{\mathrm{a}}$ & .841 & .787 & .45341
\end{tabular}

a. Predictors: (Constant), Organizational Climate, Emotional Intelligence

The strength of the relationship can be understood with the help of value $\mathrm{R}(0.835)$, which indicates that collectively, the impact of EI and OC on OCB was $83.5 \%$ and that the relationship among EI, OC, and OCB was strong. The value of R-squared indicated the amount of variation in the dependent variable that could be explained by the independent variable; therefore, EI and OC were able to explain $84.1 \%$ of changes caused in OCB.

Table 5 explains the ANOVA of the model designed for this research, which included EI and OC as the independent variables and OCB as the dependent variable. The F-value (204.996) means that the model chosen for this research was statistically fit. To be considered significant, the sig value should be less than 0.05 . In this case, the sig value was 0.000 ; hence, the null hypothesis in this case was rejected. In other words, EI had a significant impact on OCB. 
Table 5. Regression Analysis - Table of ANOVA

ANOVA ${ }^{a}$

\begin{tabular}{ccccccc}
\hline & Model & Sum of Squares & df & Mean Square & F & Sig. \\
\hline $\mathbf{1}$ & Regression & 84.285 & 2 & 42.143 & 204.996 & $.000^{\mathrm{b}}$ \\
& Residual & 71.336 & 347 & .206 & & \\
& Total & 155.621 & 349 & & &
\end{tabular}

a. Dependent Variable: Organizational Citizenship behavior

b. Predictors: (Constant), Organizational Climate, Emotional Intelligence

Table 6 reveals the coefficient values of the variables and the impact of EI on OCB and OC on OCB, respectively. The results indicated that $\mathrm{OC}$ had a significant impact on $\mathrm{OCB}$, and EI also impacted OC. The sig values for OC and EI were 0.000 and 0.030 , respectively. Table 6 reveals that one unit change in OC caused about $97.4 \%$ change in OCB. From the beta value of EI, it is evident that one unit change in EI changed OCB by $43 \%$. Hence, the alternate hypothesis was accepted.

Table 6. Regression Analysis - Coefficients Table

\section{Coefficients $^{\mathrm{a}}$}

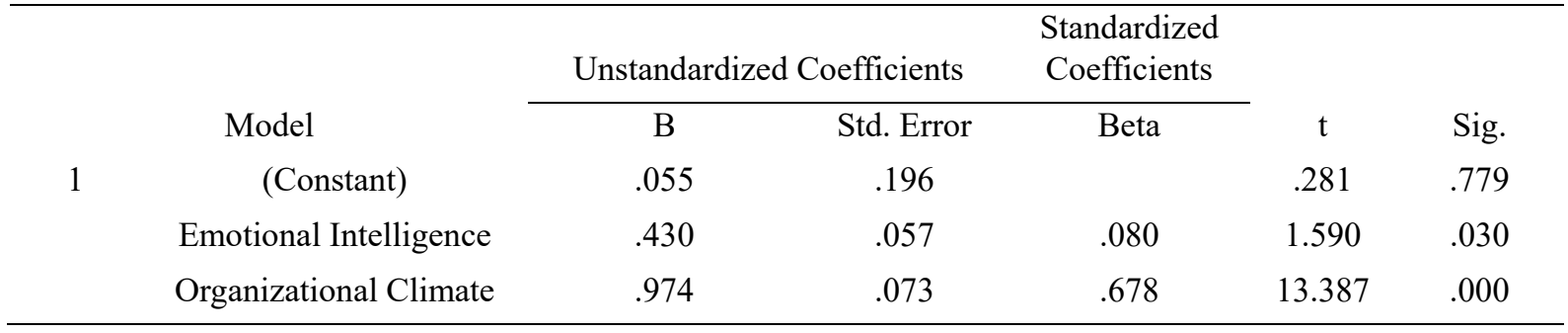

a. Dependent Variable: Organizational Citizenship Behavior

With respect to the impact of EI on OCB in relation to the mediating role of OC, the study found that OC plays an influential role by ensuring significant improvement in employee loyalty to the organization (Balouch, Fathollahzadeh, Amiri, \& Kadkhodaei, 2015). Taking this into consideration, the study found a positive relationship among the aforementioned variables; thus, the hypothesis depicting the impact of EI on the OCB was accepted. In particular, it was revealed that OCB was the result of OC, which implies that employees tend to behave negatively if dissatisfied with OC (Carmeli, 2003). Conversely, their behavior tends to be positive if satisfied with their overall job and OC (Jordan, Ashkanasy, \& Hartel, 2002).

Moreover, the study found that employees with higher EI were more inclined to help others within the organization, which could be the result of an OC that promotes mutual support (Carmeli \& Josman, 2006). OC also encourages employees to be committed to their work and overall organizational goals and objectives. On the contrary, the study also found that organization managers' and leaders' EI aids in the development of a positive OC, which eventually increases positive employee attitudes and behaviors (i.e., OCB). In particular, the regression analysis also revealed that positive OC led to a $97.4 \%$ change in overall OCB; thus, it can be suggested that OC's role in the production of OCB was significant (Cote \& Miners, 2006). It is important for organizations to ensure that employees are provided with a positive, encouraging work environment. With a positive OC, there is an increase in overall employee productivity, which contributes to organizational efficiency directly.

Employee EI also plays a major role in ensuring that OCB is achieved and employee productivity increases. Therefore, companies must develop an OC that promotes learning, success, and equality to ensure the organization can survive and thrive in the intensely competitive pharmaceutical industry. If an organization hires employees that are emotionally intelligent, it will create a positive OC and ultimately result in higher organizational productivity and improved overall performance.

Determining the relationship between EI and OCB was the second research objective. The study used (Wong \& Law, 2002) four essential factors: self-management, self-awareness, regulation of emotions, and social awareness. 
All the aforementioned factors were found to have a positive relationship with OCB.

Similarly, the study found that social awareness as a factor of EI promotes the understanding of people's emotions within the organizational setting while encouraging leaders to offer feedback to employees about appropriate emotional development (Cherniss, 2000). This not only encourages leaders to ensure a healthy working environment but also assures the regulation of emotions to avoid any negative activity that could affect the healthy working environment (MelitaPrati, Douglas, Ferris, Ammeter, \& Buckley, 2003). This implies that EI positively influenced OCB and job satisfaction, organizational commitment, and employee loyalty.

With respect to job satisfaction, EI ensures that employee needs and demands are considered. This allows leaders and managers to ensure that employees are offered a challenging work environment that leads to higher overall job satisfaction while simultaneously reducing their discomfort level that leads to reduced job satisfaction and eventually, a drastic increase in absenteeism (Hosseinian, Yazdi, Zahraie, \& Fathi-Ashtiani, 2006). Similarly, EI also addresses employees' feelings of belongingness and attachment to the organization and its affairs. In this sense, interpersonal skills aid in the functional improvement of the organization (Chiva \& Alegre, 2008) while ensuring that employees are continually empowered and encouraged to remain compatible with organizational goals and objectives. This ultimately encourages employees to move beyond the responsibilities in their job description, leading to a significant increase in employee commitment and loyalty (Thiruchelvi \& Supriya, 2009).

The primary findings of this study concluded that a correlation exists not only between EI and OCB, but that EI had a significant statistical impact on OCB. Additionally, this study specifically considered Jordanian pharmaceutical companies; from the results, it can be concluded that employees of Jordanian pharmaceutical companies tend to feel that they are an important part of the organization and therefore feel linked to the organization.

The third research objective focused on determining the relationship between EI and OC. In this regard, the study found that EI plays an influential role in the development and progress of OC; in particular, companies have directed leaders and managers to collectively work with employees to ensure a healthy climate, which could lead to overall satisfaction and loyalty towards the organization (Momeni, 2009). The study also found that when employees are provided with safe and secure working environments, they tend to focus on improving their performance and productivity in return for the growth and success of the organization. This study's findings were consistent with Awwad and Ali (2012), who found that providing employees with an appropriate and feasible climate can lead to improved organizational performance.

On the other hand, the study also revealed that EI has a dominant role in encouraging and motivating employees to change their attitudes and behaviors towards work, which eventually results in the alignment of employees' behavior with organizational objectives (Cherniss, 2001). This is turn provides the organization with an opportunity to sustain and increase their competitive advantage based on EI (Goleman, Boyatzis, \& McKee, 2001). Furthermore, EI within the organization not only encourages employees to change their attitudes and behaviors but also promotes developing positive interpersonal relationships in the organizational setting. Similarly, the study found that EI promotes the efficient, effective utilization of organizational resources for achieving operational efficacy (Patterson et al., 2005). EI in relation with OC also promotes two-way communication between leaders and employees, which further strengthens the relationship between workforce and management. This implies that EI exerts a strong, positive influence on OC. This study found a $69.6 \%$ correlation between the independent and mediating variables, indicating a relationship. Using questionnaire responses, it was found that emotionally intelligent employees positively impact OC.

The fourth objective focused on investigating and examining OC's mediating role on $\mathrm{OCB}$, wherein the concept of OCB is considered an unrestricted behavior of employees, without concern for monetary or non-monetary gains, aimed at the overall achievement of organizational goals and objectives (LePine, Erez, \& Johnson, 2002). In this regard, Kao (2017) revealed that companies have continually focused on capitalizing on their leaders to ensure that employees are offered a flexible OC in which they are continually challenged for professional and personal development. The study further revealed that an effective OC reduces the employees' intention to leave, thereby reducing the costs associated with employee recruitment and selection while providing the organization with the benefit of focusing on their core operations (Organ, Podsakoff, \& MacKenzie, 2005).

In this regard, this study also found that $\mathrm{OC}$ encourages positive $\mathrm{OCB}$ among employees within an organization. In particular, $\mathrm{OC}$ encourages employees to develop positive images of the organization and to remain satisfied with their job and the overall processes and procedures (Zellars, Tepper, \& Duffy, 2002); thus, the organization is able to achieve its mutually shared goals and objectives in the most profitable manner (Rioux \& Penner, 2001). However, the study also found that management's attitude plays an important role in either positively or negatively 
influencing employees. In particular, if the organization fails to create such a climate in which employees are provided with equal opportunity, equal treatment, and growth opportunities, they tend to develop a negative perception of the company, which eventually leads to their dissatisfaction and disloyalty (Zellars et al., 2002). On the contrary, successful creation of climate based on the aforementioned factors motivates employees to become more cooperative, while showing respect toward others irrespective of their position (i.e., hierarchy); therefore, it can be argued based on the findings that $\mathrm{OC}$ and $\mathrm{OCB}$ are positively dependent on each other.

The findings also suggested that $\mathrm{OC}$ is a source of motivation for employees to develop OCB; however, the study revealed that OCB among employees cannot be motivated by rewards and monetary benefits, but only through a climate that promotes respect, fairness, and equality (Koys, 2001). This has ultimately made companies rely on developing a better understanding of $\mathrm{OC}$ to ensure that employees are treated equally and provided with equal opportunities for success.

This study's primary results indicated that in the case of Jordanian pharmaceutical companies, OC is of great importance because it tends to promote efficiency and effectiveness among employees. This is because OC was found to be the mediator between EI and OCB. Particularly, the results of the regression analysis and correlation analysis revealed a strong link among both variables. Thus, it can be concluded that $\mathrm{OC}$ does in fact play a mediating role among EI and OCB; if emotionally intelligent employees are provided with positive OC, only then can they contribute positively towards OCB.

\section{Discussion}

The relationship between the independent and dependent variables indicated that social awareness is one of the most important elements of EI that encourages freedom of expression. The findings indicated that the relationship between the variables is also the result of the mediating factors. OC reveals that the overall culture of the organization is the result of employee interaction within the company. Furthermore, Cherniss (2000) has shown that it is necessary to understand employees' emotions and how leaders encourage them to perform better. Leaders are well aware of the fact that employees require a positive working environment where they feel secure and satisfied. MelitaPrati et al. (2003) has described that the regulation of emotions is the result of how well employees are given the leverage to express their feelings. Findings revealed that employees should be able to express their emotions within the organization to convey their message. However, this implies that EI plays a significant role in bringing about change in OCB as well as other factors, including employee loyalty and job satisfaction.

According to Hosseinian et al. (2006), EI helps employees fulfill their needs and demands, which further gives the responsibility to managers and leaders to offer a distinctive working environment that could satisfy employees. The descriptive analysis and results of correlation and regression showed that a positive relationship exists between both variables. The results also indicated that EI assisted in inculcating feelings of belonging and attachment with the organization; if employees are not able to associate their role with the job environment, they would not express loyalty and dedication.

Furthermore, findings indicated that correlation and regression depicted the strong impact of one variable on another. However, the results of descriptive analysis have also shown their impact on how much EI influences OCB. The overall culture of the organization is the result of feedback received from leaders and how well employees adjust to the work environment. Momeni (2009) indicated that if employees are provided with safe and secure working environments, they tend to focus on improving their performance and productivity in return for the growth and success of the organization. Despite the fact that organizational culture is the result of EI, it is not necessary that employees are encouraged towards a culture that encourages freedom and expression.

The in-depth analysis of the statistical measures showed that EI encouraged a change in employees in their behavior and attitude, but it also promoted change in employees towards their organization. It was indicated that EI develops a positive relationship with other members of the organization. Patterson et al. (2005) indicates that EI also contributes to the utilization of resources to achieve organizational productivity.

On the basis of the study's findings and the above discussion, it was revealed that $\mathrm{OC}$ acted as a mediating factor in the relationship between EI and OCB. For instance, it indicated that OC was basically a two-way communication between employees and organization leadership. Overall, the study results showed that the strong relationship between the independent and dependent variable indicated a strong role of the mediating factor. Though there were various factors of the study that influenced their role as mediators, OC was the main factor that showed how a sound organizational culture is developed. Furthermore, it was also found that the result of correlation and regression indicates the association between both the variables. 


\subsection{Practical Implications}

For the betterment of employees and the organization itself, firms should focus on the individual development of employees. As discussed in previous sections, the dimensions of EI are self-awareness, self-management, social awareness, and regulation of emotions; hence, for practical implementation, management should focus on developing the necessary skills that are required for employee growth and control over emotions to carry out tasks. This could not only help in employee retention but also help motivate them to work beyond their job description.

However, it has become a challenge for companies to integrate some of these strategies. Practically, this study was helpful in understanding how OCB has become a factor for enhancing job satisfaction. Therefore, pharmaceutical companies in Jordan should focus on developing a culture where employees are able to achieve their goals and feel satisfied. Moreover, employees working in pharmaceutical companies often complain of a dull environment where they feel uncomfortable. Hence, it is recommended that on practical grounds, companies should ensure that employees are constantly being tracked for their satisfaction regarding work, culture, and overall environment of the organization.

\subsection{Limitations}

The researcher faced various limitations during the process of gathering relevant data. Since the study was based on EI and OCB, the researcher had to gather authentic data from pharmaceutical company employees in Jordan. Some of the key limitations were the restricted duration of the study and difficulty in gathering information from the respondents due to the complexity of internal procedures.

\subsection{Recommendations and Future Research}

The first recommendation relates to OC development based on equality and fairness. Since employees can easily become unmotivated and dissatisfied in a company setting, motivation and self-awareness programs should be encouraged by management. Managers and leaders must ensure that employee needs and demands with respect to the climate are continually taken into consideration. Employees should be given the leverage to express their opinions and emotions, treated equally, and provided an opportunity to grow. This may help in not only retaining employees but also in motivating them to work beyond their job description. In doing so, pharmaceutical companies would reduce the possibility of lower performance and productivity, which could ultimately help create a competitive advantage in the industry. Companies should develop social interaction between employees and other coworkers and social activities should be conducted. Companies should encourage employees to participate actively in organization-based tasks that help them acquire necessary skills.

The next recommendation to reduce negative impact on pharmaceutical companies would be to include special training plans for employees to aid in understanding the importance of self-knowledge and expressing emotions in a logical manner. Since managers and leaders are in direct contact with employees, training and development opportunities would help them to understand and evaluate employee behavior. Employees should be given the leverage to express their opinions and emotions within the organizational setting, providing leaders and managers with an ability to take appropriate actions to keep employees satisfied and motivated within the OC. Employees with varying levels of EI should be identified at an early stage so that they are managed appropriately. For instance, if an employee's absenteeism rate is increasing, a training and development opportunity would help managers and leaders to understand the underlying issues. Additionally, they would have an opportunity to take appropriate action to reduce or eliminate such behavior by improving the overall working conditions and other non-monetary factors.

Future research could be improved by adopting a qualitative method of research design. A qualitative study using thematic analysis could improve results by using journals and articles for gathering information regarding EI and OCB.

Interview analysis is another effective way to improve study results. In addition, the research specifically applies to Jordan; to gather a larger pool of information regarding EI and the influence it has on OCB, the study should be conducted on a global scale using secondary sources, ranging from existing journals and articles to books.

\section{Conclusion}

This study successfully found that OC plays a vital role in encouraging and motivating employees to exhibit loyalty towards their organization. The aforementioned variables of the study developed a positive relationship with each other and the hypotheses were accepted, indicating that the impact of EI on organizational behavior is positive. The overall perception after data collection and analysis was that if the employees are not satisfied with OC, they will not be able to grow and be productive. Employee performance depends on how they are treated and the type of environment provided for them. 


\section{Acknowledgments}

I would like to acknowledge the pharmaceutical companies in Jordan for allowing me to conduct study their employees. I am also grateful for their cooperation and for their help in facilitating the distribution and gathering of data.

\section{References}

Abraham, R. (2004). Emotional competence as antecedent to performance: A contingency framework. Genetic, Social, and General Psychology Monographs, 130(2), 117-143. https://doi.org/ 10.3200/MONO.130.2.117145

Adeoye, H., \& Torubelli, V. (2011). Emotional intelligence and human relationship management as predictors of organizational commitment. IFE Psychologia, 19(2), 212-226. http://doi.org/10.4314/ifep.v19i2.69532

Ahmadizadeh, Z., Heydarinejad, S., Farzam, F., \& Boshehri, N. S. (2012). Investigation the relation between organizational climate and organizational citizenship behavior. International Journal of Sport Studies, 2(3), 163-167.

Alfonso, L., Zenasni, F., Hodzic, S., \& Ripoll, P. (2016). Understanding the mediating role of quality of work life on the relationship between emotional intelligence and organizational citizenship behaviors. Psychological Reports, 118(1), 107-127. http:// doi.org/10.1177/0033294115625262

Ali, M., Lei, S., \& Wei, X. Y. (2017). The mediating role of the employee relations climate in the relationship between strategic HRM and organizational performance in Chinese banks. Journal of Innovation \& Knowledge, 3(3), 115-122. https://doi.org/10.1016/j.jik.2016.12.003.

Anvari, R., Barzaki, A. S., Amiri, L., Irum, S., \& Shapourabadi, S. (2017). The mediating effect of organizational citizenship behavior on the relationship between workplace spirituality and intention to leave. Intangible Capital, 13(3), 615. https://doi.org/10.3926/ic.906.

Arda, O. A., Delen, D., Tatoglu, E., \& Zaim, S. (2017). An analytic approach to assessing organizational citizenship behavior. Decision Support Systems, 103(C), 9-23. http://doi.org/10.1016/j.dss.2017.08.004

Asgarian, F. S., Aghajani, M., \& Alavi, N. M. (2017). Emotional intelligence and the occurrence of accidents in motorcycle drivers in Kashan, Iran. Journal of Trauma Nursing, 24(4), 280-286. http://doi.org/10.1097/JTN.0000000000000304

Avey, J. B., Wernsing, T. S., \& Luthans, F. (2008). Can positive employees help positive organizational change? Impact of psychological capital and emotions on relevant attitudes and behaviors. The Journal of Applied Behavioral Science, 44(1), 48-70. https://doi.org/10.1177/0021886307311470

Awwad, M. S., \& Ali, H. K. (2012). Emotional intelligence and entrepreneurial orientation: The moderating role of organizational climate and employees' creativity. Journal of Research in Marketing and Entrepreneurship, 14(1), 115-136.

Balouch, S., Fathollahzadeh, R., Amiri, M. A., \& Kadkhodaei, A. (2015). Emotional intelligence and organizational citizenship behaviors. International Journal of Advanced Research, 3(4), 905-910.

Barriball, L., Fitzpatrick, J., \& Roberts, J. (2011). Emotional intelligence: Its relationship to stress, coping, wellbeing and professional performance in nursing students. Nurse Education Today, 31(8), 855-60. https://doi.org/ 10.1016/j.nedt.2010.12.023

Bernstrøm, V. H., Lone, J. A., Bjørkli, C. A., Ulleberg, P., \& Hoff, T. (2013). Assessing a Norwegian translation of the organizational climate measure. Psychological Reports, 112(2), 390-407. https://doi.org/10.2466/01.08.PR0.112.2.390-407

Biswas, N. \& Mazumder, Z. (2017). Exploring organizational citizenship behavior as an outcome of job satisfaction: A Critical Review. IUP Journal of Organizational Behavior, 16(2), 7-16.

Bonett, D. G., \& Wright, T. A. (2015). Cronbach's alpha reliability: Interval estimation, hypothesis testing, and sample size planning. Journal of Organizational Behavior, 36(1), 3-15. https://doi.org/10.1002/job.1960

Bowen, D. E., \& Ostroff, C. (2004). Understanding HRM-firm performance linkages: The role of the 'strength' of the HRM system. Academy of Management Review, 29(2), 203-221. https://doi.org/10.5465/amr.2004.12736076

Boyatzis, R. E., Goleman, D., \& Rhee, K. (2000). Clustering competence in EI: Insights from the Emotional Competence Inventory (ECI). In Bar-On, R., \& Parker, J. D. A. (Eds.), The Handbook of Emotional 
Intelligence: Theory, development, assessment, and application and home, school, and in the workplace (pp. 343-362). San Francisco, CA: Jossey-Bass.

Brenner, B. R., Lyons, H. Z., \& Fassinger, R. E. (2010). Can heterosexism harm organizations? Predicting the perceived organizational citizenship behaviors of gay and lesbian employees. Career Development Quarterly, 58(4), 321-335. https://doi.org/10.1002/j.2161-0045.2010.tb00181.x

Carmeli, A. (2003). The relationship between emotional intelligence and work attitudes, behavior and outcomes: An examination among senior managers. Journal of Managerial Psychology, 18(8), 788-813. https://doi.org/10.1108/026839403105

Carmeli, A. \& Josman, Z. E. (2006). The relationship among emotional intelligence, task performance, and organizational citizenship behaviors. Human Performance, 19(4), 403-419. https://doi.org/10.1207/s15327043hup1904_5

Carvalho, V. S., Guerrero, E., Chambel, M. J., \& González-Rico, P. (2016). Psychometric properties of WLEIS as a measure of emotional intelligence in the Portuguese and Spanish medical students. Evaluation and Program Planning, 58, 152-159. https://doi.org/10.1016/j.evalprogplan.2016.06.006

Cherniss, C. (2000). Social and emotional competence in the workplace. In Bar-On, R. \& Parker, J.D.A. (Eds.), The Handbook of Emotional Intelligence: Theory, development, assessment, and application and home, school, and in the workplace (pp. 433-458). San Francisco, CA: Jossey-Bass.

Cherniss, C. (2001). Emotional intelligence and organizational effectiveness. In Cherniss, C., \& Goleman, D. (Eds.), The emotionally intelligent workplace: How to select for, measure, and improve emotional intelligence in individuals, groups, and organizations (pp. 3-12). San Francisco, CA: Jossey-Bass.

Chiva, R., \& Alegre, J. (2008). Emotional intelligence and job satisfaction: the role of organizational learning capability. Personnel Review, 37(6), 680-701. https://doi.org/10.1108/00483480810906900

Clark, J. M., \& Polesello, D. (2017). Emotional and cultural intelligence in diverse workplaces: getting out of the box. Industrial and Commercial Training, 49(7/8), 337-349.

Cote, S., \& Miners, C. T. (2006). Emotional intelligence, cognitive intelligence, and job performance. Administrative Science Quarterly, 51(1), 1-28. https://doi.org/10.2189/asqu.51.1.1

Daher, A., \& Alabbadi, I. (2017). Investigating the effect of Syrian refugees on the pharmaceutical sector in Jordan. Archives of Iranian Medicine, 20(8), 538-546.

Goleman, D. (2000). Leadership that gets results. Harvard Business Review, 78(2), 4-16.

Goleman, D., Boyatzis, R., \& McKee, A. (2001). Primal leadership: The hidden driver of great performance. Harvard Business Review, 79(11), 42-51.

Grandey, A. A., \& Gabriel, A. S. (2015). Emotional labor at a crossroads: where do we go from here? Annual Review of Organizational Psychology and Organizational Behavior, 2, 323-349. https://doi.org/10.1146/annurev-orgpsych-032414-111400

Gül, H. (2008). Organizational climate and academic staff's perception on climate factors. Humanity \& Social Sciences Journal, 3(1), 37-48.

Hakim, W., \& Fernandes, A. (2017). Moderation effect of organizational citizenship behavior on the performance of lecturers. Journal of Organizational Change Management, 30(7), 1136-1148. https://doi.org/10.1108/JOCM-11-2016-0242

Hinton, P. R., McMurray, I., \& Brownlow, C. (2014), SPSS explained. New York, NY: Routledge.

Hosseinian, S., Yazdi, S. M., Zahraie, S., \& Fathi-Ashtiani, A. (2008). Emotional intelligence and job satisfaction. Journal of Applied Sciences, 8(5), 903-906. http://doi.org/ 10.3923/jas.2008.903.906

Indarti, S., Solimun, A. A. R. F., \& Hakim, W. (2017). The effect of OCB in relationship between personality, organizational commitment and job satisfaction on performance. Journal of Management Development, 36(10), 1283-1293.

Jauhari, H., \& Singh, S. (2013). Perceived diversity climate and employees' organizational loyalty. Equality, Diversity and Inclusion: An International Journal, 32(3), 262-276. https://doi.org/10.1108/EDI-12-20120119

Jordan, P. J., Ashkanasy, N. M., \& Hartel, C. E. (2002). Emotional intelligence as a moderator of emotional and behavioral reactions to job insecurity. Academy of Management Review, 27(3), 361-372. 
Kao, R. H. (2017). The relationship between work characteristics and change-oriented organizational citizenship behavior: A multi-level study on transformational leadership and organizational climate in immigration workers. Personnel Review, 46(8), 1890-1914. https://doi.org/10.1108/PR-01-2016-0012

Kauts, A. \& Chechi, V. K. (2014). Teacher Effectiveness in Relation to Type of Institution. Emotional Intelligence and Teaching Experience. Anadolu Journal of Educational Sciences International, 4(2), 63-81.

Kegan, R., Lahey, L., Fleming, A., \& Miller, M. (2014). Making business personal. Harvard Business Review, 92(4), 44-52.

Khalili, A. (2016). Linking leaders' emotional intelligence competencies and employees' creative performance and innovative behavior: Evidence from difference nations. International Journal of Innovation Management, 20(7), 1650069. https://doi.org/10.1142/S1363919616500699

Khalili, A. (2017). Transformational leadership and organizational citizenship behavior: The moderating role of emotional intelligence. Leadership \& Organization Development Journal, 38(7), 1004-1015. https://doi.org/10.1108/LODJ-11-2016-0269

Klopotan, I., Buntak, K., \& Drožđek, I. (2016). Employee loyalty: differences between genders and the public and the private sector. Interdisciplinary Description of Complex Systems: INDECS, 14(3), 303-313.

Koning, L. F., \& Van Kleef, G. A. (2015). How leaders' emotional displays shape followers' organizational citizenship behavior. The Leadership Quarterly, 26(4), 489-501.

Koys, D. J. (2001). The effects of employee satisfaction, organizational citizenship behavior, and turnover on organizational effectiveness: A unit-level, longitudinal study. Personnel Psychology, 54(1), 101-114.

Lau, P. Y. Y., Tong, J. L. T., Lien, B. Y. H., Hsu, Y. C., \& Chong, C. L. (2017). Ethical work climate, employee commitment and proactive customer service performance: Test of the mediating effects of organizational politics. Journal of Retailing and Consumer Services, 35, 20-26.

Lee, K. \& Allen, N. J. (2002). Organizational citizenship behavior and workplace deviance: the role of affect and cognition. Journal of Applied Psychology, 87(1), 131-142.

LePine, J. A., Erez, A., \& Johnson, D. E. (2002). The nature and dimensionality of organizational citizenship behavior: a critical review and meta-analysis. Journal of Applied Psychology, 87(1), 52-65.

Lewis, S. J., Eccles, G. R., Mackay, S. J., \& Robinson, J. (2017). Emotional intelligence throughout the lifecycle of Australian radiographers. Radiologic Technology, 89(1), 12-19.

Libbrecht, N., Lievens, F., \& Schollaert, E. (2010). Measurement equivalence of the Wong and Law Emotional Intelligence Scale across self and other ratings. Educational and Psychological Measurement, 70(6), 10071020. https://doi.org/10.1177/0013164410378090

Maamari, B. E., \& Messarra, L. C. (2012). An empirical study of the relationship between organizational climate and organizational citizenship behavior. European Journal of Management, 12(3), 165-173.

MelitaPrati, L., Douglas, C., Ferris, G. R., Ammeter, A. P., \& Buckley, M. R. (2003). Emotional intelligence, leadership effectiveness, and team outcomes. The International Journal of Organizational Analysis, 11(1), 21-40.

Menard, S. (2002). Applied logistic regression analysis (Vol. 106). Thousand Oaks, CA: SAGE.

Minibas-Poussard, J., Le Roy, J., \& Erkmen, T. (2017). The moderating role of individual variables in the relationship between organizational justice and organizational commitment. Personnel Review, 46(8), 16351650. http://doi.org/ 10.1108/PR-12-2015-0311

Mittal, E. V., \& Sindhu, E. (2012). Emotional intelligence and leadership. Global Journal of Management and Business Research, 12(16), 35-38.

Momeni, N. (2009). The relation between managers' emotional intelligence and the organizational climate they create. Public Personnel Management, 38(2), 35-48. https://doi.org/10.1177/009102600903800203

Muldoon, J., Keough, S. M., \& Liguori, E.W. (2017). The role of job dedication in organizational citizenship behavior performance. Management Research Review, 40(10), 1042-1057.

Naldöken, Ü. \& Tengilimoğlu, D. (2017). A field study on determining the effects of organizational climate in terms of social interaction on knowledge management at health organizations. Journal of Economics \& Management, 29, 75-101. 
Nunnally, J. C. (1978). Psychometric theory (2nd ed.). New York, NY: McGraw-Hill.

Omoregbee, I., Morrison, B. W., \& Morrison, N. M. (2016). A case for using ability-based emotional intelligence measures in the selection of trainee psychologists. Business Perspectives and Research, 4(1), 1-14. https://doi.org/10.1177/2278533715605425

Organ, D. W. (1988). Organizational citizenship behavior: The good soldier syndrome. Lexington, MA: Lexington Books/D.C. Heath and Com.

Organ, D. W., Podsakoff, P. M., \& MacKenzie, S. B. (2005). Organizational citizenship behavior: Its nature, antecedents, and consequences. Thousand Oaks, CA: SAGE.

Parke, M. R. \& Seo, M. G. (2017). The role of affect climate in organizational effectiveness. Academy of Management Review, 42(2), 334-360. https://doi.org/10.5465/amr.2014.0424

Patterson, M. G., West, M. A., Shackleton, V. J., Dawson, J. F., Lawthom, R., Maitlis, S...\& Wallace, A. M. (2005). Validating the organizational climate measure: links to managerial practices, productivity and innovation. Journal of Organizational Behavior, 26(4), 379-408.

Podsakoff, N. P., Whiting, S. W., Podsakoff, P. M., \& Blume, B. D. (2009). Individual-and-organizational-level consequences of organizational citizenship behaviors: A meta-analysis. Journal of Applied Psychology, 94(1), 122-141. http://doi.org/10.1037/a0013079.

Rafiei, M. (2017). The effect of emotional quotient on the organizational citizenship behavior in some Iranian hospitals. Kybernetes, 46(7), 1189-1203.

Randhawa, G., \& Kaur, K. (2015). An empirical assessment of impact of organizational climate on organizational citizenship behaviour. Paradigm, 19(1), 65-78. https://doi.org/10.1177/0971890715585202

Ratner B., (2009). The correlation coefficient: Its values range between $+1-1$, or do they?", Journal of Targeting, Measurement and Analysis for Marketing, 17(2), 139-142

Rioux, S. M., \& Penner, L. A. (2001). The causes of organizational citizenship behavior: A motivational analysis. Journal of Applied Psychology, 86(6), 1306-1314.

Salovey, P., \& Mayer, J. D. (1990). Emotional intelligence. Imagination, Cognition and Personality, 9(3), 185-211. https://doi.org/10.2190/DUGG-P24E-52WK-6CDG

Schneider, B. (2000). The psychological life of organizations. In Ashkanasy, N.M. \& Peterson, M.F. (Eds.), Handbook of Organizational Culture and Climate (pp. 17-21). Thousand Oaks, CA: SAGE.

Sekaran, U., \& Bougie R. (2016). Research methods for business: A skill building approach (7th ed.). Wiley.

Shafiq, M., \& Rana, R. A. (2016). Relationship of emotional intelligence to organizational commitment of college teachers in Pakistan. Eurasian Journal of Educational Research, 62, 1-14.

Taherinejad, Z., Ahmadi, S. A., Amani, R., \& Khoshouei, M.S. (2017). Relationship emotional intelligence and personality traits with organizational commitment among Iranian nurses. Journal of Research \& Health, 7(1), 614-623.

Talachi, R. K., Gorji, M. B., \& Boerhannoeddin, A. B. (2014). An investigation of the role of job satisfaction in employees' organizational citizenship behavior. Collegium Antropologicum, 38(2), 429-436.

Thiruchelvi, A., \& Supriya, M. V. (2009). Emotional intelligence and job satisfaction. Asia Pacific Business Review, 5(2), 109-115. https://doi.org/10.1177/097324700900500209

Tinti, J. A., Venelli-Costa, L., Vieira, A. M., \& Cappellozza, A. (2017). The impact of human resources policies and practices on organizational citizenship behaviors. BBR-Brazilian Business Review, 14(6), 636-653. http://dx.doi.org/10.15728/bbr.2017.14.6.6

Tofighi, M., Tirgari, B., Fooladvandi, M., Rasouli, F., \& Jalali, M. (2015). Relationship between emotional intelligence and organizational citizenship behavior in critical and emergency nurses in South East of Iran. Ethiopian Journal of Health Sciences, 25(1), 79-88.

Tsai, Y., \& Wu, S. W. (2010). The relationships between organisational citizenship behaviour, job satisfaction and turnover intention. Journal of Clinical Nursing, 19(23-24), 3564-3574. http://doi.org/10.1111/j.13652702.2010.03375.x

Turnipseed, D. L., \& Vandewaa, E. A. (2012). Relationship between emotional intelligence and organizational $\begin{array}{llll}\text { citizenship behavior. } & \text { Psychological }\end{array}$ 
https://doi.org/10.2466/01.09.20.21.PR0.110.3.899-914

Van Kleef, G. A., Van Doorn, E. A., Heerdink, M. W., \& Koning, L. F. (2011). Emotion is for influence. European Review of Social Psychology, 22(1), 114-163. https://doi.org/10.1080/10463283.2011.627192

Waruwu, B. (2015). The correlation between teachers' perceptions about principal's emotional intelligence and organizational climate and job satisfaction of teachers of state senior high school in Gunungsitoli Nias, Indonesia. Journal of Education and Practice, 6(13), 142-147.

Whitman, D. S., Van Rooy, D. L., \& Viswesvaran, C. (2010). Satisfaction, citizenship behaviors, and performance in work units: A meta-analysis of collective construct relations. Personnel Psychology, 63(1), 41-81. http://dx.doi.org/10.1111/j.1744-6570.2009.01162.x

Wolff, S. B., Pescosolido, A. T., \& Druskat, V. U. (2002). Emotional intelligence as the basis of leadership emergence in self-managing teams. The Leadership Quarterly, 13(5), 505-522. http://dx.doi.org/10.1016/S1048-9843(02)00141-8

Wong, C., \& Law, K. (2002). The effects of leader and follower emotional intelligence on performance and attitude: An exploratory study. The Leadership Quarterly, 13(3), 243-274. http://doi.org/ doi10.1016/S10489843(02)00099-1

Zellars, K. L., Tepper, B. J., \& Duffy, M. K. (2002). Abusive supervision and subordinates' organizational citizenship behavior. Journal of Applied Psychology, 87(6), 1068. http://doi.org/10.1037//00219010.87.6.1068

Zhang, S., \& Shi, Q. (2017). The relationship between subjective well-being and workplace ostracism: The moderating role of emotional intelligence. Journal of Organizational Change Management, 30(6), 978-988. https://doi.org/10.1108/jocm-07-2016-0139

\section{Copyrights}

Copyright for this article is retained by the author(s), with first publication rights granted to the journal.

This is an open-access article distributed under the terms and conditions of the Creative Commons Attribution license (http://creativecommons.org/licenses/by/3.0/). 